\title{
Reply to: Olanzapine: Sancho Panza for clinicians who care for patients with advanced cancer
}

\author{
Signe Harder ${ }^{1}$ (D) $\cdot$ Mogens Groenvold ${ }^{2} \cdot$ Jørn Herrstedt ${ }^{3}$ \\ Received: 9 December 2019 / Accepted: 20 December 2019 /Published online: 10 January 2020 \\ (C) Springer-Verlag GmbH Germany, part of Springer Nature 2020
}

We thank Drs. Alkan and Tanriverdi for their interest in our study of olanzapine in the treatment of nausea and vomiting $(\mathrm{N} / \mathrm{V})$ in advanced cancer patients. As stated by their letter to the Editor: "Harder et al. provided us an effective drug against $\mathrm{N} / \mathrm{V}$. With further studies, we will be able to identify a specific group of patients to whom we can provide better palliation of N/V with olanzapine." [1] We appreciate this conclusion and agree on many of the comments made, but wish to elaborate on some of them:

We agree that the cause of nausea and vomiting in the palliative setting is multifactorial and sometimes difficult to identify. This poses two main difficulties: a) high heterogeneity yields a low number of subjects in each group during a trial (hence low power), and b) many possible causes mean more complex and time-consuming diagnostics and longer time of suffering for the patient. In our opinion, we need a combination of an etiology-based approach to some of the common and treatable causes and the use of a "fit most patients" antiemetic for the rest. In future studies, use of multiple exclusion criteria should be limited in order to move the field of research closer to everyday clinical life.

It is correct that a number of patients received metoclopramide, but patients entering the study did not continue metoclopramide, meaning that a drug-drug interaction with olanzapine was unlikely considering the short $\mathrm{T}^{1} 12$ of metoclopramide. The olanzapine dose tested was quite high $(10 \mathrm{mg})$, but we experienced no extra-pyramidal symptoms

Signe Harder

Signe.Harder@rsyd.dk

1 Department of Oncology, Odense University Hospital, Odense, Denmark

2 Department of Palliative Medicine, Bispebjerg and Frederiksberg Hospitals \& University of Copenhagen, Copenhagen, Denmark

3 Department of Clinical Oncology and Palliative Care Units, Zealand University Hospital Roskilde, Roskilde, Denmark even in patients receiving metoclopramide as a rescue antiemetic.

We agree that data on opioid use and other co-medications during the trial would have been preferable, but we wanted to make the study simple (in this fragile population) in order to be able to also include patients from home. We prioritized to make the patient population as close to real-life patients as possible, minimizing the workload for patients and their relatives going through a very stressful time. This is another challenge in doing research within the field of palliative care, where ethics and feasibility are paramount. As Alkan and Tanriverdi state: "we need more drugs and more palliative maneuvers to provide better comfort for our patients". Continuous research is therefore highly needed, and we hope our study has inspired to do so.

\section{Compliance with ethical standards}

Conflict of interest The authors declare that they have no conflicts of interest.

\section{Reference}

1. Alkan A, Tanrıverdi Ö (2019) Olanzapine: Sancho Panza for clinicians who care for patients with advanced cancer. Support Care Cancer. Published online 24 October 2019

Publisher's note Springer Nature remains neutral with regard to jurisdictional claims in published maps and institutional affiliations. 